\title{
INTERCOMPARISON OF SNOW SAMPLING AND ANALYSIS WITHIN THE ALPINE-WIDE SNOWPACK INVESTIGATION (SNOSP)
}

\author{
M. SCHWIKOWSKI ${ }^{1, *}$ A. NOVO ${ }^{2}$, U. BALTENSPERGER ${ }^{1}$, R. DELMAS ${ }^{3}$, \\ H. W. GÄGGELER' ${ }^{1}$ A. KASPER ${ }^{4}$, M. KUHN $^{5}$, F. MAUPETIT $^{3}$, U. NICKUS ${ }^{5}$,

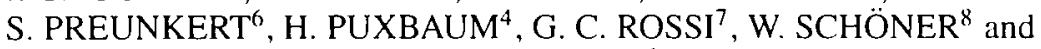 \\ D. WAGENBACH ${ }^{6}$ \\ ${ }^{1}$ Paul Scherrer Institut, CH-5232 Villigen PSI, Switzerland \\ ${ }^{2}$ ENEL-CRAM, Unità Studi e Monitoraggi Ambientali, I-20134 Milano, Italy \\ ${ }^{3}$ Laboratoire de Glaciologie et Geophysique de l'Environnement CNRS, F-38402 Saint Martin \\ d'Hères Cedex, France \\ ${ }^{4}$ Institut für Analytische Chemie, Technische Universitüt Wien, A-1060 Wien, Austria \\ ${ }^{5}$ Institut für Meteorologie und Geophysik der Universität Innsbruck, A-6020 Innshruck, Austria \\ ${ }^{6}$ Institut für Umweltphysik der Universität Heidelberg. D-69120 Heidelberg, Germany \\ ${ }^{7}$ ENEL-CRIS, Unità Idrologia Impiantistica, 1-30172 Venezia-Mestre, Italy \\ ${ }^{8}$ Institut für Meteorologie und Geophysik, A-l190 Wien, Austria
}

(Received 9 May, 1995; accepted 10 October, 1995)

\begin{abstract}
In order to investigate the seasonal and geographical distribution of snow concentrations and deposition fluxes of environmentally relevant ionic species in the Alps, the international program SNOSP was initiated. In the framework of this program, intercomparisons of snow sampling techniques and analytical methods to determine the ionic species $\mathrm{Cl}^{-}, \mathrm{NO}_{3}^{-}, \mathrm{SO}_{4}^{2-}, \mathrm{K}^{+}, \mathrm{Na}^{+}, \mathrm{NH}_{4}^{+}$, $\mathrm{Mg}^{2+}$, and $\mathrm{Ca}^{2+}$, as well as the $\mathrm{pH}$ and the specific conductivity were performed. The concentrations of these species in the snow samples collected in the SNOSP program varied by orders of magnitude with, e.g., concentrations of $\mathrm{NO}_{3}^{-}, \mathrm{SO}_{4}^{2-}$, and $\mathrm{NH}_{4}^{+}$ranging from $0.2-60,0.2-90$, and $0.1-60 \mu \mathrm{eq}$ $\mathrm{L}^{-1}$, respectively. The intercomparisons revealed a reasonable agreement of the determinations of the species $\mathrm{Cl}^{-}, \mathrm{NO}_{3}^{-}, \mathrm{SO}_{4}^{2-}, \mathrm{Na}^{+}$, and $\mathrm{NH}_{4}^{+}$in snow. Results were less satisfactory for $\mathrm{K}^{+}, \mathrm{Mg}^{2+}$, $\mathrm{Ca}^{2+}$, and $\mathrm{H}^{+}$, mainly due to the very low concentrations. In conclusion, recommendations are formulated for the reliable derivation of chemical inventories from snow packs.
\end{abstract}

Key words: Snow sampling, snow chemistry, intercomparison, Alps

\section{Introduction}

Snowpacks accumulate both wet and dry deposition of chemical trace species and are unique natural monitors of precipitation chemistry and atmospheric fluxes (see e.g., Laird et al., 1986). Nevertheless, a few requirements should be met by the snowpack chosen as monitor, i.e., the snow must persist for a sufficiently long time period, no meltwater percolation or rain should destroy the chemical stratigraphy in the snowpack, and contamination by trace species from local pollution should not occur. Thus, snowpacks at remote sites in the high mountains, for instance in the Alps, would seem to be excellent choices for snow chemistry investigations. However, because of the remoteness of these alpine sites, only a few investigations have

- To whom correspondence should be addressed. 
been performed to date. In addition, studies have been mainly focused on "cold" glaciers, i.e., glaciers where the snow accumulates throughout the year without any significant modification of its isotopic or chemical stratigraphy. In the Alps, such cold glaciers can only be found at sites higher than $4000 \mathrm{~m}$ a.s.l. (Funk, 1994), thus, the information currently available does not cover the whole geographical range of the Alps (see e.g., Oeschger et al., 1977, Delmas and Aristarain, 1978, Haeberli et al., 1983, Batifol and Boutron, 1984, Schotterer et al., 1985, Ronseaux and Delmas, 1988, Delmas et al., 1988, Wagenbach et al., 1988, Wagenbach and Geis, 1989, de Angelis and Gaudichet, 1991, Maupetit and Delmas, 1994a, b, Maupetit et al., 1995). To summarize, although a comprehensive data set exists for a few high-altitude sites in the Alps, the geographical resolution is rather poor. Thus, a data set covering the whole alpine range would be highly desirable, particularly if one takes into account the dimensions of the alpine range, its geographical situation (surrounded by the heaviest industrialized areas in Europe) and its function as a barrier of the transboundary transport of pollutants (Camuffo et al., 1991), as well as the importance of alpine glaciers and snowfields as freshwater reservoirs. Even though several national and international precipitation monitoring networks have been operating in the surrounding regions providing data for use as input to atmospheric transport and deposition models, the Alps are still not a well-known area with respect to precipitation and deposition chemistry.

Consequently, in the framework of EUROTRAC, the subproject ALPTRAC was initiated to investigate the occurrence, transformation and deposition of atmospheric constituents within the high altitude environment of the Alps (Puxbaum, 1991). One major tool in ALPTRAC, to improve the understanding of the atmospheric deposition patterns in the Alps, is the alpine-wide investigation of the winter snow pack chemistry. This program known as SNOSP is mainly devoted to the seasonal and geographical distribution of snow concentrations and deposition fluxes of environmentally relevant trace species at high elevation sites, i.e., above $3000 \mathrm{~m}$ a.s.l. (Puxbaum, 1991).

Within SNOSP, for the first time, snow concentrations and deposition fluxes of ionic species were determined concurrently from various glaciers in the French, Swiss, Italian and Austrian Alps. The program has been active since 1990 with two snow-pit sampling campaigns per year - one in early March for the winter situation and one in May for the spring situation - at a number of different sites (1990: 6 sites, 1991: 14 sites, 1992: 14 sites, 1993: 9 sites). As a result, a comprehensive set of data now exists, which allows the investigation of the seasonal and geographical distribution of the snow impurity content.

The data revealed by the SNOSP program are presented in two papers. In this paper, details on sampling techniques and analytical methods, as well as the results of two laboratory intercomparisons and two snow-pit sampling intercomparison campaigns are discussed. A description of the sampling sites and the general results with respect to seasonal trends, geographical distributions and interannual variations are presented in Nickus et al. (1996). 
A great effort was made within SNOSP laboratories to ensure the quality and comparability of the SNOSP data. This is not an easy task since the concentrations of trace species in snow can vary by at least two orders of magnitude and in particular can be very low in clean winter snow with concentrations similar to summer averages reported for south Greenland surface snow $\left(0.1\right.$ to $2 \mu \mathrm{eq} \mathrm{L} \mathrm{L}^{-1}$ of $\mathrm{NH}_{4}^{+}, \mathrm{NO}_{3}^{-}$, and $\mathrm{SO}_{4}^{2-}$, see also Puxbaum and Wagenbach, 1994 and references therein). Compared to annual average concentrations of major ions in precipitation at low elevation sites $(<1000 \mathrm{~m})$ in the eastern Alps, the concentrations in highalpine winter snow can be a factor 10 to 100 lower (Puxbaum et al., 1991). These snow samples with very low impurity concentrations are particularly sensitive with respect to stability and contamination. Furthermore, the higher porosity of snow compared to ice, for example, requires special care in sample handling, since contaminating gases can more easily diffuse into the snow. Thus, special precautions must be taken to minimize contamination during sampling and sample handling. In addition, the samples should not melt before chemical analysis, and the time period from the sampling to the analyses should be kept as short as possible. Particularly problematic are Saharan dust layers which occur in the snowpack, since the deposition of the dust can be vary inhomogeneous even on the small scale of a snow-pit. After melting, the corresponding snow samples still contain insoluble, alkaline mineral dust particles. Usually, these samples are either analyzed after filtration, and only the dissolved fraction of e.g., $\mathrm{Ca}^{2+}$ is determined (see e.g., Maupetit and Delmas, 1994b), or they are analyzed without previous filtration by techniques requiring acidification, for example inductively coupled plasma optical emission spectrometry. Although a good agreement between both techniques has been reported for concentrations of $\mathrm{Ca}^{2+}$ below $40 \mu \mathrm{eq} \mathrm{L}{ }^{-1}$ (Döscher et al., 1995), this may not be true for higher concentrations.

To control the quality of the chemical analyses, two laboratory intercomparisons were performed, the first in November/December 1991 with eight participating laboratories analyzing two standard samples and the second in April/May 1992 with nine participating laboratories analyzing one surface snow sample. To compare not only the analytical methods but also the snow-pit sampling techniques, two field intercomparison campaigns, with real snow samples collected by the individual groups, were conducted. The first field intercomparison took place at Daunferner in the Austrian Alps on March 3, 1989, and the second field intercomparison at Weissfluhjoch, Davos, in the eastern part of the Swiss Alps on March 30, 1993. Both laboratory and field intercomparisons were mainly focused on the measurements of the major ionic species $\left(\mathrm{Cl}^{-}, \mathrm{NO}_{3}^{-}, \mathrm{SO}_{4}^{2-}, \mathrm{K}^{+}, \mathrm{Na}^{+}, \mathrm{NH}_{4}^{+}, \mathrm{Mg}^{2+}\right.$, and $\mathrm{Ca}^{2+}$ ) as well as $\mathrm{pH}$ and specific conductivity. The results are reported here including a description of the analytical methods used by the individual groups. In addition, the quality of chemical analyses performed during the second field intercomparison was tested by a cross-comparison of the ion and conductivity balances. Finally, the overall findings are used to formulate recommendations for future snow impurity studies. 


\section{Experimental}

\subsection{SNOW-PIT SAMPLING}

The first snow-pit sampling intercomparison was organized by the Institute for Meteorology and Geophysics, University of Innsbruck (IMGI) and performed at Daunferner on March 3, 1989. The Daunferner glacier site is located at $2960 \mathrm{~m}$ a.s.l. in the Stubai Alps, Tyrol, Austria. The six participating groups (BLB, ENEL, IMGW/IAC-TUW, IMGI, IUP, LGGE; for explanation of the abbreviations see list at the end of the paper) collected snow samples from snow-pits dug separately, one beside the other, at a flat, northeast oriented slope. Only IMGI and BLB collected their samples from the same pit. IMGW and IAC-TUW participated in a collaboration - IMGW was responsible for the sampling and IAC-TUW for the chemical analyses. Generally, sampling was performed along a vertical profile down to the late summer horizon of the previous year. From the pit wall, samples were cut out using plastic or stainless steel instruments. Increments varied from group to group (from 2.6 to $70 \mathrm{~cm}$ ). One group conducted the sampling point-wise, i.e., $2.6 \mathrm{~cm}$ increments every $10 \mathrm{~cm}$. Samples were either directly transported and stored in the plastic tubes used for cutting out or transferred into plastic bags. Samples were kept frozen until analysis by the individual groups. Prior to the analysis the samples were melted within the tubes or bags. Analyses were carried out within a few hours after melting and concentrations of the ions $\mathrm{Cl}^{-}, \mathrm{NO}_{3}^{-}$, $\mathrm{SO}_{4}^{2-}$, and $\mathrm{NH}_{4}^{+}$were required to be determined. Special precautions to minimize sample contamination were taken. Materials assumed to come in contact with the collected snow (like bottles, tubes, bags, shovels, vials, etc.) had been carefully cleaned in the laboratories before. To illustrate the sampling procedure, examples of the individual techniques used by two different groups (I and II) are given:

I: Sampling was carried out using a rectangular stainless steel sampler (dimensions: $20 \times 30 \mathrm{~cm}$ wide, with $5 \mathrm{~cm}$ high edges). The snow samples were cut by a stainless steel blade and immediately transferred into a PE bag. Each bag was sealed by a knot, labeled, and closed again in a second bag. Bags were not pre-washed in the laboratory, since, during a previous check carried out by rinsing some bags with ultrapure water, no contamination was observed. The same sampler was used to obtain separate samples for the immediate determination of the snow density. The bags containing the samples were stored in a prechilled refrigerator and transported to the laboratory. They were directly melted in the plastic bags just before chemical analysis. After the analyses the samples were frozen again.

II: Snow samples were collected from the pit wall using precleaned Plexiglas instruments and plastic bags. Operator wore clean gloves and clothes, and a non-emissive particle mask. The snow samples directly transferred from the Plexiglas tube to the plastic bag were untouched by the operator during collection. They were brought back to the laboratory in a frozen condition. 
The samples were melted directly in their plastic bag, a few minutes before parallel ion chromatographic analysis of cations and anions. They were later transferred to precleaned, air-tight glass flasks and stored in a frozen state. All the sampling, handling and analysis operations were performed under ultraclean conditions in clean rooms.

Details of the analytical methods used by the different groups are given in Table I. The snow density was determined by IMGW only.

The second joint snow-pit sampling campaign with six participating groups (ENEL, IMGW/IAC-TUW, IMGI, IUP, LGGE, PSI) was performed on March 30, 1993. at the snow investigation field of the Swiss Institute for Snow and Avalanche Research, Weissfluhjoch, Davos, Switzerland. This field is located at $2540 \mathrm{~m}$ a.s.l., about $1000 \mathrm{~m}$ above the town of Davos. The snow investigation field at Weissfluhjoch was chosen for the snow-pit sampling intercomparison because earlier studies at this site revealed that the spatial snow deposition is quite uniform and that very few perturbations of the snow stratigraphy by high wind speeds occur (Baltensperger et al., 1993). Samples were collected by each group individually within a joint snow-pit. The distance between the sampling positions was about $1 \mathrm{~m}$. Sampling increments were $10 \mathrm{~cm}$, down to a depth of at least $1.4 \mathrm{~m}$, with an average number of 16 samples obtained by each group. Every group used their individual sampling technique described principally in the previous paragraph. In addition, two further snow samples were collected - one from the surface and one from a depth of $1 \mathrm{~m}$ - and melted in the field to homogenize the snow. These two samples were distributed among the participating groups in precleaned tubes and served as analytical control samples. In the following, these samples will be referred to as Standard 1 (surface snow) and Standard 2 (snow from $1 \mathrm{~m}$ depth). During sampling and sample handling. similar precautions were taken to those of the first intercomparison. In the snow samples, $\mathrm{Cl}^{-} . \mathrm{NO}_{3}^{-}, \mathrm{SO}_{4}^{--} . \mathrm{Na}^{+} . \mathrm{NH}_{4}^{+}$, $\mathrm{K}^{+}, \mathrm{Mg}^{2+}, \mathrm{Ca}^{2+}, \mathrm{pH}$ and specific conductivity were determined. The analytical methods are again described in Table I. The snow density was measured for each sample by the individual groups by weighing a known volume of snow.

\subsection{LABORATORY INTERCOMPARISONS}

For the first laboratory intercomparison in November/December 1991, two standard samples were distributed among the eight participating groups (BLB, ENEL, IAC-TUW, IMGI, IUP, LGGE, OFZS, PSI). The first sample consisted of diluted hydrochloric acid $\left(27.5 \mu \mathrm{eq} \mathrm{L}^{-1}\right.$ of $\mathrm{H}^{+}$and $\mathrm{Cl}^{-}$, respectively), while the second sample was prepared by diluting sodium chloride, sodium nitrate and sodium sulfate in demineralized water giving concentrations of $\mathrm{Cl}^{-}, \mathrm{NO}_{3}^{-}$, and $\mathrm{SO}_{4}^{2-}$ of 14.1 . 48.7 , and $62.7 \mu \mathrm{eq} \mathrm{L}^{-1}$, respectively. The samples had to be analyzed for $\mathrm{pH}$ and for their $\mathrm{Cl}^{-}, \mathrm{NO}_{3}^{-}$and $\mathrm{SO}_{4}^{2-}$ concentrations. The intercomparison showed good agreement with measured values close to the theoretical values of the concentration of $\mathrm{Cl}^{-}$in the first sample (average: $28.4 \mu \mathrm{eq} \mathrm{L}^{-1}$, relative standard deviation: $3 \%$. 


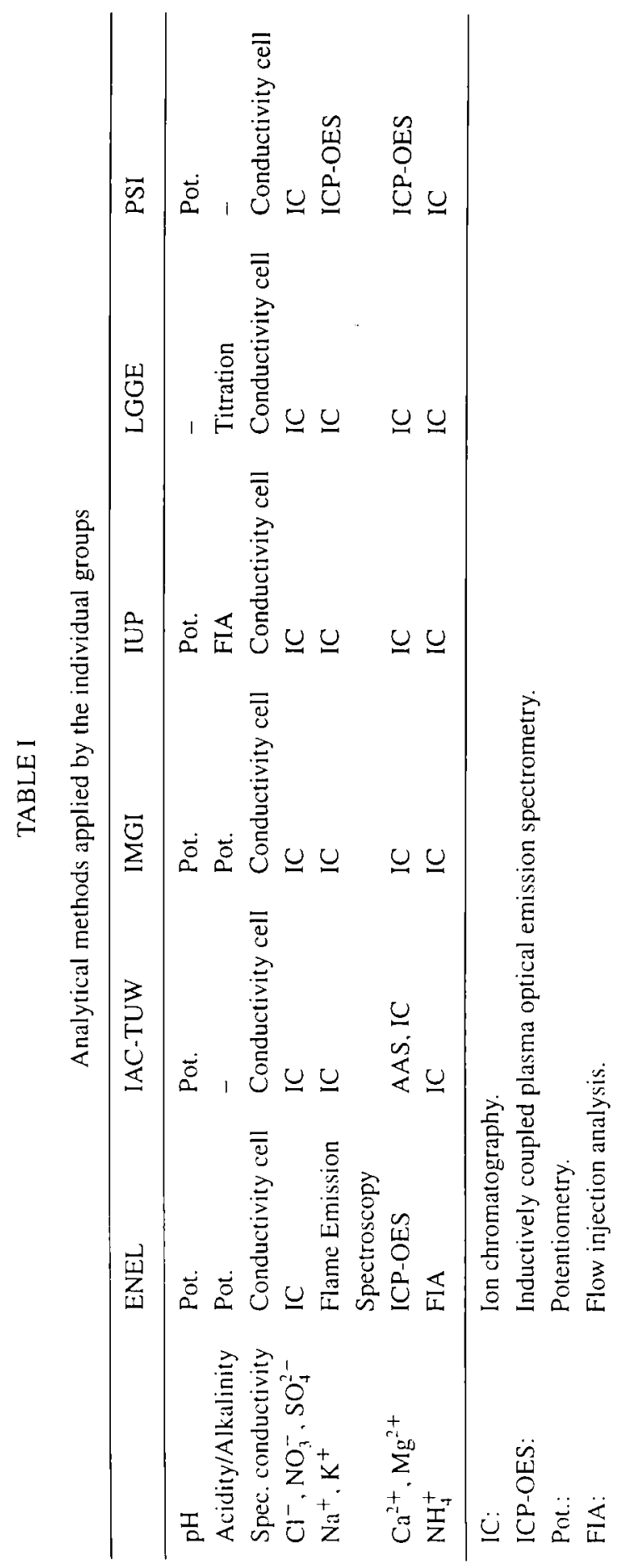


one outlier removed) and of the concentrations of the anions in the second sample with averages of $13.7,44.7$, and $60 \mu \mathrm{eq} \mathrm{L}^{-1}$, and relative standard deviations of 13,13 , and $7 \%$ for $\mathrm{Cl}^{-}, \mathrm{NO}_{3}^{-}$, and $\mathrm{SO}_{4}^{2-}$, respectively. The average calculated or measured $\mathrm{H}^{+}$concentration was $20.4 \mu \mathrm{eq} \mathrm{L} \mathrm{L}^{-1}$ with a relative standard deviation of $37 \%$ in the first sample (analysis performed by five groups only) and $2.5 \mu \mathrm{eq} \mathrm{L} \mathrm{L}^{-1}$ with a relative standard deviation of $0 \%$ in the second sample (analysis performed by four groups only), indicating problems in determining $\mathrm{pH}$ in samples with low ionic strength. The second laboratory intercomparison was performed in April/May 1992, with a surface snow sample collected at Untersberg in Salzburg, Austria. The sample was distributed among the nine participating groups (BLB, ENEL, GSF, IAC-TUW, IMGI, IUP, LGGE, ÖFZS, PSI) after melting and filtration. It had to be analyzed for its $\mathrm{Cl}^{-}, \mathrm{NO}_{3}^{-}, \mathrm{SO}_{4}^{2-}, \mathrm{Na}^{+}, \mathrm{NH}_{4}^{+}$, and $\mathrm{K}^{+}$concentrations as well as for $\mathrm{pH}$ and specific conductivity. The average concentrations of the ionic constituents were $11,44,23,8,11,1.2$, and $31 \mu \mathrm{eq} \mathrm{L}-1$ of $\mathrm{Cl}^{-}, \mathrm{NO}_{3}^{-}, \mathrm{SO}_{4}^{2-}, \mathrm{Na}^{+}, \mathrm{NH}_{4}^{+}$, $\mathrm{K}^{+}$, and $\mathrm{H}^{+}$, respectively. The second intercomparison confirmed the results of the first intercomparison with relative standard deviations of 12,5 , and $10 \%$ for the anions $\mathrm{Cl}^{-}$(two outliers removed), $\mathrm{NO}_{3}^{-}$(two outliers removed), and $\mathrm{SO}_{4}^{2-}$ (one outlier removed). The outliers removed were reported as insecure data by the participating laboratories. The relative standard deviation of the $\mathrm{H}^{+}$concentration, either calculated from the $\mathrm{pH}$ or measured directly, was $40 \%$ (one outlier removed). Measurements of the specific conductivity agreed well with an average value of $18 \mu \mathrm{S} \mathrm{cm}^{-1}$ and a relative standard deviation of $12 \%$ (one outlier removed). The determinations of the cations $\mathrm{Na}^{+}, \mathrm{NH}_{4}^{+}$, and $\mathrm{K}^{+}$showed relative standard deviations of 23,18 , and $33 \%$, respectively. Generally, larger relative standard deviations were observed for cations than for anions indicating that some laboratories were less experienced in cation analyses.

\section{Results of the Snow-Pit Sampling Intercomparison at Daunferner}

The conventional SNOSP procedure to compare the results from different snow-pits is to calculate the precipitation or volume weighted means given in $\mu \mathrm{eq} \mathrm{L}^{-1}$ and the total depositions or ionic loads given in meq $\mathrm{m}^{-2}$ for the respective species (see e.g., Maupetit et al., 1993). For both calculations the density of snow is needed as an additional parameter to the depth of the snow sample in the snow-pit. However, the snow density profile was measured by one group only, and therefore this density profile was applied to the other snow-pits at the relevant sampling depths. Sampling intervals of the individual groups ranged from a few $\mathrm{cm}$ up to $70 \mathrm{~cm}$. Only four groups reached the late summer horizon of the previous year the depth of which varied from 1.65 to $1.95 \mathrm{~m}$. This is a reasonable agreement taking into account the natural inhomogeneity of the snow accumulation even on the small scale of the snow-pit sampling. The results of BLB were excluded because of poor coverage. The data analysis of the remaining five groups was restricted to an actual snow depth 


\section{TABLE II}

Volume weighted mean values ( $\mu$ eq $\mathrm{L}^{-1}$ ) calculated for all measured components of the snow-pit sampling intercomparison at Daunferner. Results are given for each group, along with averages (AVG) and relative standard deviations in\% (STD). In addition, the actual depths of the individual snow-pits considered for this calculation are shown together with the number of sampling increments

\begin{tabular}{llccccc}
\hline Group & $\begin{array}{l}\text { Depth } \\
(\mathrm{cm} \text { snow })\end{array}$ & $\begin{array}{l}\text { Number of } \\
\text { increments }\end{array}$ & $\begin{array}{l}\mathrm{Cl}^{-} \\
\left(\mu \mathrm{eq} \mathrm{L} \mathrm{L}^{-1}\right)\end{array}$ & $\begin{array}{l}\mathrm{NO}_{3}^{-} \\
\left(\mu \mathrm{eq} \mathrm{L} \mathrm{L}^{-1}\right)\end{array}$ & $\begin{array}{l}\mathrm{SO}_{4}^{2-} \\
\left(\mu \mathrm{eq} \mathrm{L} \mathrm{L}^{-1}\right)\end{array}$ & $\begin{array}{l}\mathrm{NH}_{4}^{+} \\
\left(\mu \mathrm{eq} \mathrm{L} \mathrm{L}^{-1}\right)\end{array}$ \\
\hline 1 & 90 & 6 & 1.13 & 5.59 & 2.30 & 2.20 \\
2 & 90 & 9 & 4.90 & 6.02 & 2.36 & 3.10 \\
3 & 90 & 18 & 3.09 & 5.65 & 2.20 & 2.60 \\
4 & 91 & 13 & 0.67 & 3.93 & 1.60 & 3.02 \\
5 & 90 & 6 & 5.05 & 7.54 & 13.1 & 3.41 \\
AVG & & & 2.97 & 5.75 & $2.12 \mathrm{a}$ & 2.87 \\
STD (\%) & & 69 & 18 & 16 & 16 \\
\hline
\end{tabular}

AVG without value from group 5.

of $90 \mathrm{~cm}$ since the late summer horizon of the previous year was not reached by all groups. Volume weighted mean concentrations of the ions $\mathrm{Cl}^{-}, \mathrm{NO}_{3}^{-} \cdot \mathrm{SO}_{4}^{2-}$. and $\mathrm{NH}_{4}^{+}$, calculated from these five groups amounted to $2.97,5.75,2.12$, and $2.87 \mu \mathrm{eq}$ $\mathrm{L}^{-1}$, respectively. In Table II the individual values are given for each group along with the averages and relative standard deviations. Weighted mean concentrations of $\mathrm{NO}_{3}^{-}, \mathrm{SO}_{4}^{2-}$ (one outlier removed) and $\mathrm{NH}_{4}^{+}$showed a reasonable agreement. Although the weighted mean concentrations were significantly lower than those measured in the laboratory intercomparison samples (by factors between 4 and 11 ), detection limits were only approached for two samples. In the case of these two samples, the concentration was assumed to be half of the detection limit. Thus, the variation might have been induced by the different sampling and sample handling protocol applied by the groups, e.g., by the point-wise sampling conducted by one group, or by analytical errors. Mean concentrations of $\mathrm{Cl}^{-}$showed very high discrepancies, but is not clear whether they were caused by contamination during sampling or by analytical problems.

To summarize, this snow-pit sampling intercomparison revealed the importance of precise chemical analyses in order to meet the requirements of the SNOSP program and of improved sampling protocols, particularly with respect to contamination control. In addition, snow density measurements and continuous rather than point-wise samplings of the whole snow-pit profile were shown to be essential in order to determine ionic loads or atmospheric deposition fluxes from snow packs. 

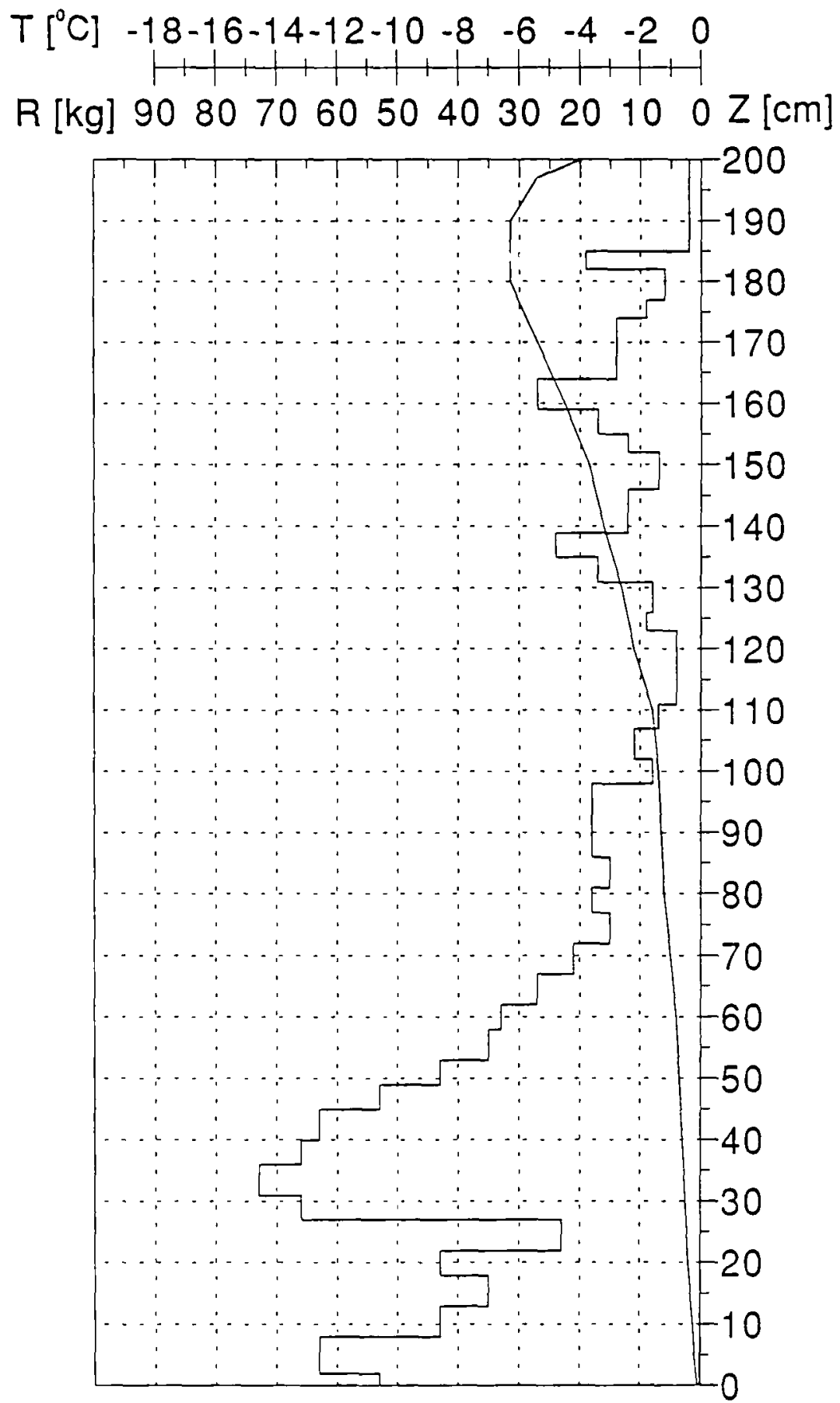

Fig. 1. Vertical ram distance $(R)$ and firn temperature $(T)$ plotted versus height above ground $(Z)$ of the snow pack at the snow investigation field. Weissfluhjoch, measured by the Swiss Institute for Snow and Avalanche Research on March, 31, 1993. 
TABLE III

Average concentrations (AVG) of the individual components in $\mu \mathrm{eq} \mathrm{L}^{-1}$ in the analytical control samples Standard 1 and Standard 2 collected at Weissfluhjoch calculated from the results obtained by the different groups. Besides the average, the standard deviations (STD) are given in $\mu \mathrm{eq} \mathrm{L}^{-1}$ and $\%$

\begin{tabular}{|c|c|c|c|c|c|c|c|c|c|}
\hline & $\mathrm{Cl}^{-}$ & $\mathrm{NO}_{3}^{-}$ & $\mathrm{SO}_{4}^{2-}$ & $\mathrm{K}^{+}$ & $\mathrm{Na}^{+}$ & $\mathrm{NH}_{4}^{+}$ & $\mathrm{Ca}^{2+}$ & $\mathrm{Mg}^{2+}$ & $\mathrm{H}^{+}$ \\
\hline \multicolumn{10}{|l|}{ Standard 1} \\
\hline AVG $\left(\mu \mathrm{eq} \mathrm{L}^{-1}\right)$ & 3.99 & 22.3 & 6.61 & 0.14 & 2.34 & 9.21 & 2.57 & 1.1 .3 & 21.3 \\
\hline $\operatorname{STD}\left(\mu \mathrm{eq} \mathrm{L}^{-1}\right)$ & 0.34 & 2.29 & 0.94 & 0.07 & 0.27 & 0.81 & 0.34 & 0.71 & 14.9 \\
\hline $\operatorname{STD}(\%)$ & 9 & 10 & 14 & 52 & 11 & 9 & 13 & 63 & 70 \\
\hline \multicolumn{10}{|l|}{ Standard 2} \\
\hline $\operatorname{AVG}\left(\mu \mathrm{eq} \mathrm{L}^{-1}\right)$ & 2.75 & 7.97 & 8.25 & 0.18 & 1.85 & 5.08 & 3.76 & 2.31 & 9.5 \\
\hline $\operatorname{STD}\left(\mu \mathrm{eq} \mathrm{L}^{-1}\right)$ & 0.23 & 0.25 & 0.62 & 0.12 & 0.31 & 0.34 & 0.43 & 0.55 & 5.5 \\
\hline STD (\%) & 8 & 3 & 7 & 70 & 17 & 7 & 11 & 24 & 58 \\
\hline
\end{tabular}

\section{Results of the Snow-Pit Sampling Intercomparison at Weissfluhjoch}

\subsection{Characterization OF THE SNOW PaCK}

The Swiss Institute for Snow and Avalanche Research conducts regular snow profile measurements at their snow investigation field. The measurements include the temperature profile, the vertical ram resistance and a snow crystal characterization in the individual discernible layers (see e.g., Colbeck et al., 1985). Results from temperature profile and vertical ram resistance measurements on March, 31, 1993 that is one day after the sampling for the intercomparison - are shown in Figure 1. The snow pack was characterized by a temperature between 0 and $-6{ }^{\circ} \mathrm{C}$, an increasing ram resistance with depth and an ice layer of a few $\mathrm{cm}$ thickness $20 \mathrm{~cm}$ below the surface. A Saharan dust layer at approximately $80 \mathrm{~cm}$ below the surface was visually identified and chemically indicated by its high $\mathrm{Ca}^{2+}$ concentration. Concentrations of $\mathrm{NO}_{3}^{-}, \mathrm{SO}_{4}^{2-}$, and $\mathrm{NH}_{4}^{+}$, as well as of $\mathrm{Na}^{+}$and $\mathrm{Cl}^{-}$were higher in the upper part of the snow pack and represented spring conditions, whereas the quite low concentrations in the deeper part of the snow pack were typical for winter conditions (see e.g., Nickus et al., 1996). To illustrate the typical pattern, the concentrations of $\mathrm{Cl}^{-}, \mathrm{NO}_{3}^{-}, \mathrm{SO}_{4}^{2-}, \mathrm{Na}^{+}, \mathrm{NH}_{4}^{+}$, and $\mathrm{Ca}^{2+}$ as a function of the depth of the snow pack in mm water equivalents measured by one group are shown in Figure 2. To conclude, the snow pack investigated during the intercomparison was quite suitable for this purpose, since it showed all the characteristics that are usually found at the SNOSP sites. 

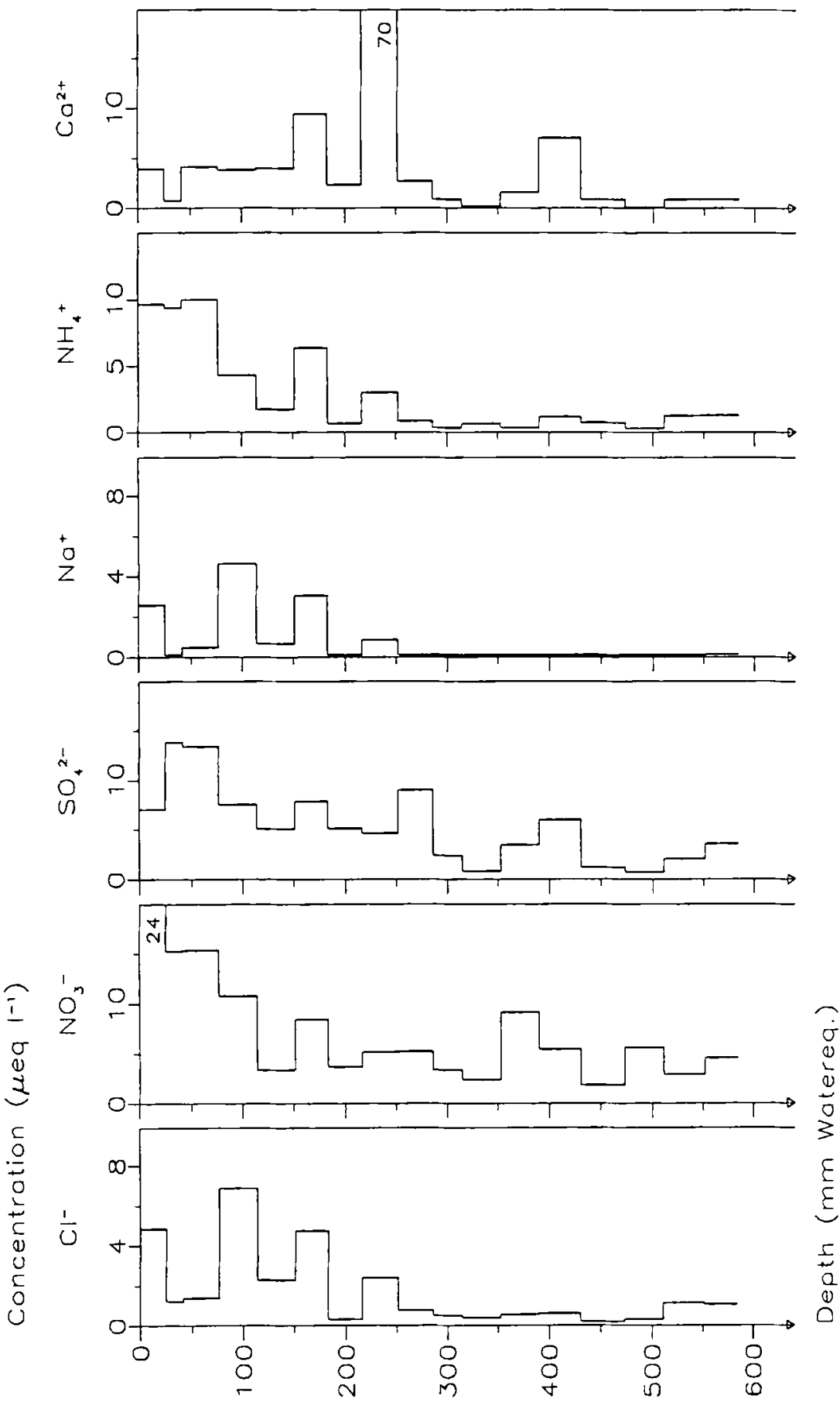

Fig. 2. Concentrations of $\mathrm{Cl}^{-}, \mathrm{NO}_{3}^{-}, \mathrm{SO}_{4}^{2-}, \mathrm{Na}^{+}, \mathrm{NH}_{4}^{+}$, and $\mathrm{Ca}^{2+}$ in $\mu \mathrm{eq} \mathrm{L}^{-1}$ as a function of the depth of the snow pack in mm water equivalents measured by group 4 at Weissfluhjoch. The Saharan dust layer is identified by its very high $\mathrm{Ca}^{2+}$ concentration and the spring snow by the increased concentrations of $\mathrm{Cl}^{-}, \mathrm{NO}_{3}^{-}, \mathrm{SO}_{4}^{2-}, \mathrm{Na}^{+}$, and $\mathrm{NH}_{4}^{+}$, compared to the winter snow. 


\subsection{RESULTS FROM THE ANALYTICAL CONTROL SAMPLES STANDARD 1 AND STANDARD 2}

From the analytical results produced by the individual laboratories for Standard samples 1 and 2, average values and standard deviations were calculated for all measured components (Table III). Specific conductivity was determined by two groups only and is therefore not included in Table III. The agreement was good for the anions $\mathrm{Cl}^{-}, \mathrm{NO}_{3}^{-}$and $\mathrm{SO}_{4}^{2-}$ as well as the cations $\mathrm{Na}^{+}, \mathrm{NH}_{4}^{+}$and $\mathrm{Ca}^{2+}$ with relative standard deviations of about $10 \%$. Agreements were less satisfying for $\mathrm{Mg}^{2+}, \mathrm{K}^{+}$and the $\mathrm{H}^{+}$concentrations that were calculated from $\mathrm{pH}$ (measured by four groups only) with relative standard deviations between 24 and $70 \%$. In the case of $\mathrm{K}^{+}$, concentrations were close to the limits of detection of some laboratories which might explain the high variability. The results of the analytical control samples were in general agreement with the laboratory intercomparisons, thus, they represent the analytical capabilities of the laboratories with respect to these kind of samples. Accordingly, these results are fundamental and limiting for the investigations of the snow-pit sampling techniques.

\subsection{RESULTS FROM THE SNOW-PIT SAMPLES}

To illustrate the similarities but also the differences of the concentration protiles determined by the individual groups, the $\mathrm{SO}_{4}^{2-}$ profiles are shown in Figure 3. Obviously, the general feature with high concentrations in the upper part and low concentrations in the deeper part was reproduced by all groups. Furthermore, single layers can be traced back from profile to profile. However, discrepancies that were most likely induced by incorrect density or depth measurements are also visible.

The data of the snow-pit sampling were processed following the conventional SNOSP procedure as described in chapter 3 . Ionic loads and volume weighted means were calculated over the sampled depth ( 1.40 to $1.46 \mathrm{~m}$ ). The discrepancy in depth was induced by the individual sampling increments. The actual sampling depth in the snow-pit was used instead of the depth in $m$ water equivalent in order to allow an intercomparison of the density measurements. Ionic loads calculated for all investigated components as well as total water accumulation calculated from sampling heights and snow densities obtained by each participating group are presented in Table IV, along with averages and relative standard deviations. All values were used for averaging, including also obvious outliers.

Measurements of the snow density agreed well, with a relative standard deviation of $6 \%$ for the calculated total water accumulation in water equivalents (see Table IV).

To differentiate between the variations introduced by the analytical determinations and the variations introduced by the sampling procedure, relative standard deviations of the ionic loads and of the analytical control samples were compared for the individual components. The components were then classified into three 


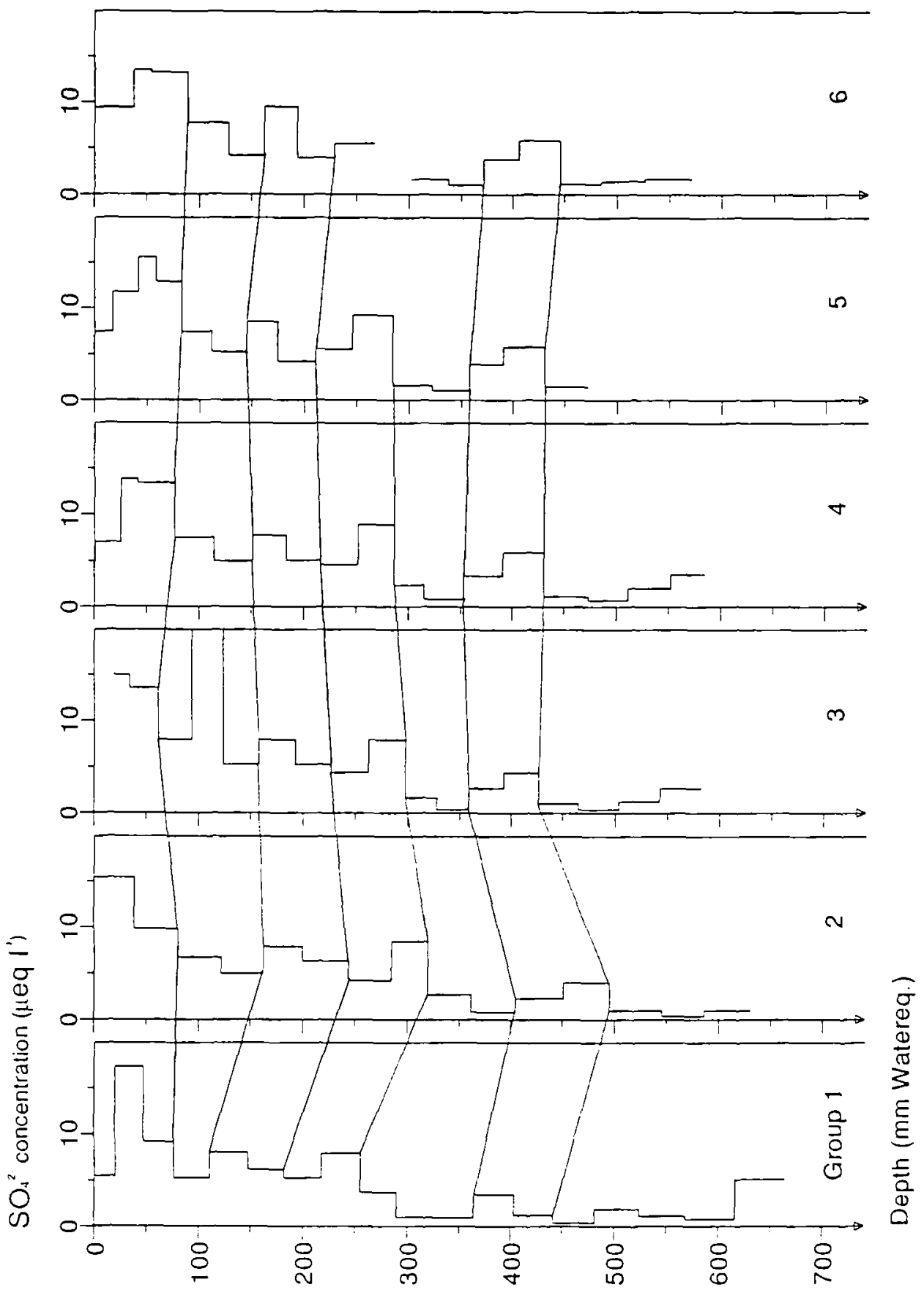

Fig. 3. $\mathrm{SO}_{4}^{2-}$ concentrations ( $\mu$ ey $\mathrm{L}^{-1}$ ) as a function of the depth of the snow pack in mm water equivalents, as measured by six individual groups at Weissfluhjoch. A few discernible layers with either high or low concentrations are indicated. 


\section{TABLE IV}

Ionic loads (meq $\mathrm{m}^{-2}$ ) calculated for all measured components as well as total water accumulation (water equivalents) calculated from the sampling height and the density of the Weissfluhjoch intercomparison. Results are given for each group and the group numbers correspond to the actual position in the snow-pit. In addition, averages (AVG) and relative standard deviations in \% (STD) are shown

\begin{tabular}{lllllllllll}
\hline Group & $\begin{array}{l}\text { Water eq. } \\
(\mathrm{mm})\end{array}$ & $\mathrm{Cl}^{-}$ & $\mathrm{NO}_{3}^{-}$ & $\mathrm{SO}_{4}^{2-}$ & $\mathrm{K}^{+}$ & $\mathrm{Na}^{+}$ & $\mathrm{NH}_{4}^{+}$ & $\mathrm{Ca}^{2+}$ & $\mathrm{Mg}^{2+}$ & $\mathrm{H}^{+}$ \\
\hline 1 & 482 & 0.67 & 3.49 & $2.42^{\mathrm{a}}$ & $0.06^{\mathrm{a}}$ & 0.33 & $1.37^{\mathrm{a}}$ & 1.58 & 0.38 & 3.96 \\
2 & 545 & 0.95 & 4.32 & 3.00 & 0.03 & 1.08 & 1.60 & 2.07 & 0.50 & 6.81 \\
$3^{\mathrm{b}}$ & 455 & 0.91 & 2.69 & 2.28 & $0.12^{\mathrm{a}}$ & 0.53 & 1.36 & 2.31 & 0.81 & 2.29 \\
4 & 473 & 0.88 & 3.47 & 2.73 & 0.03 & 0.43 & 1.45 & 3.92 & 1.14 & 1.63 \\
5 & 472 & 0.73 & 3.29 & 2.86 & $0.04^{\mathrm{a}}$ & 0.48 & 1.76 & 1.93 & 0.60 & 3.80 \\
$6^{\mathrm{c}}$ & 485 & 1.02 & 3.49 & 2.63 & $0.05^{\mathrm{a}}$ & 0.50 & 1.67 & 1.70 & 0.50 & - \\
Average & 485 & 0.86 & 3.46 & 2.65 & 0.06 & 0.56 & 1.54 & 2.25 & 0.66 & 3.70 \\
STD (\%) & 6 & 16 & 15 & 10 & 62 & 47 & 11 & 38 & 42 & 54 \\
\hline
\end{tabular}

"Concentrations partly below detection limits, detection limits were used for calculations.

${ }^{b}$ First $10 \mathrm{~cm}$ of surface snow not analyzed.

' 2 samples not analyzed for cations, 1 sample not analyzed for anions.

classes. Class 1 (consisting of the ions $\mathrm{Cl}^{-}, \mathrm{NO}_{3}^{-}, \mathrm{SO}_{4}^{2-}, \mathrm{Na}^{+}$, and $\mathrm{NH}_{4}^{+}$) was characterized by a good agreement between the relative standard deviations of the ionic loads and the analytical control samples and by low values of the relative standard deviations $(\leq 17 \%)$. $\mathrm{Na}^{+}$was considered as constituent of class 1 , since the high relative standard deviation of the ionic load was caused by one group only (relative standard deviation without group 2: 17\%). Analytical problems in determining $\mathrm{Na}^{+}$were reported by this group and this is also indicated by the cation excess seen in the quality test (see section 4.4). Thus, the slight variations of the class 1 ionic loads obtained by different groups were due to the analytical error. This corroborates the suitability of the snow sampling technique for the corresponding ions. The results for class 1 demonstrated also that the local variability of the snow field at Weissfluhjoch was low for the corresponding ions, i.e., that a local variation could not be identified within the analytical errors. Class 2 (consisting of $\mathrm{K}^{+}, \mathrm{Mg}^{2+}$, and $\mathrm{H}^{+}$) showed also a good agreement between the relative standard deviations of ionic loads and analytical control samples, but the values were substantially higher ( 42 to $67 \%$ ). Again, variations between ionic loads were caused by anaiytical errors, since concentrations of $\mathrm{K}^{+}$, and $\mathrm{Mg}^{2+}$ were low and in the range of the limits of detection of some laboratories. For class 3 (consisting of $\mathrm{Ca}^{2+}$ ) the relative standard deviation of the ionic load was about three times higher than of the analytical control samples. The high variability was caused by one value of the ionic loads (group 4). Responsible for this one high value was the Saharan dust layer. This is due to a high local variability induced by the Saha- 


\section{TABLE V}

Volume weighted mean values ( $\mu \mathrm{eq} \mathrm{L}^{-1}$ ) calculated for all measured components of the Weissfluhjoch intercomparison. Results are given for each group and the group numbers correspond to the actual position in the snow-pit. In addition, averages (AVG) and relative standard deviations in \% (STD) along with the depth of the profile in the snow-pit are shown

\begin{tabular}{lllllllllll}
\hline Group & $\begin{array}{l}\text { Depth } \\
(\mathrm{m})\end{array}$ & $\mathrm{Cl}^{-}$ & $\mathrm{NO}_{3}^{-}$ & $\mathrm{SO}_{4}^{2-}$ & $\mathrm{K}^{+}$ & $\mathrm{Na}^{+}$ & $\mathrm{NH}_{4}^{+}$ & $\mathrm{Ca}^{2+}$ & $\mathrm{Mg}^{2+}$ & $\mathrm{H}^{+}$ \\
\hline 1 & 1.40 & 1.38 & 7.24 & $5.01^{\mathrm{a}}$ & $0.13^{\mathrm{a}}$ & 0.68 & $2.85^{\mathrm{a}}$ & 3.29 & 0.80 & 8.21 \\
2 & 1.40 & 1.75 & 7.92 & 5.51 & 0.05 & 1.98 & 2.94 & 4.92 & 0.92 & 12.5 \\
$3^{\mathrm{b}}$ & 1.40 & 2.00 & 5.91 & 5.01 & 0.26 & $1.16^{\mathrm{a}}$ & $2.98^{\mathrm{a}}$ & 5.08 & 1.79 & 5.05 \\
4 & 1.41 & 1.86 & 7.34 & 5.78 & 0.06 & 0.91 & 3.07 & 8.30 & 2.41 & 3.45 \\
5 & 1.45 & 1.54 & 6.98 & 6.05 & $0.09^{\mathrm{a}}$ & 1.02 & 3.73 & 4.09 & 1.28 & 8.05 \\
$6^{\mathrm{C}}$ & 1.46 & 2.10 & 7.19 & 5.43 & $0.10^{\mathrm{a}}$ & 1.02 & 3.43 & 3.51 & 1.04 & - \\
AVG & 1.42 & 1.77 & 7.10 & 5.47 & 0.12 & 1.13 & 3.17 & 4.87 & 1.37 & 7.45 \\
STD & 2 & 15 & 9 & 8 & 67 & 40 & 11 & 38 & 45 & 47 \\
\hline
\end{tabular}

"Concentrations partly below detection limits, detection limits were used for calculations.

${ }^{h}$ First $10 \mathrm{~cm}$ of surface snow not analyzed.

‘ 2 samples not analyzed for cations. 1 sample not analyzed for anions.

ran dust layer for species present in the dust. The local variability is reflected in the continuous trend of the $\mathrm{Ca}^{2+}$ loads observed in the pit. In addition, different groups used different analytical methods for determining $\mathrm{Ca}^{2+}$ (ICP-OES and IC, see Table I). In the analytical control samples, $\mathrm{Ca}^{2+}$ concentrations measured by ion chromatography were lower than those measured by ICP-OES, indicating that a part of the $\mathrm{Ca}$ was insoluble. When $\mathrm{Ca}^{2+}$ loads were calculated after removing the Saharan samples from each profile, the relative standard deviation was reduced to $19 \%$. Consequently, it seems necessary for a $\mathrm{Ca}$ inventory of a snow pack to consider episodic events like Saharan dust layers separately.

The statements made for the ionic loads are also valid for the calculated volume weighted means, since the basis of the calculation (snow density and chemical composition) is the same (see Table V).

\subsection{QUALITY TESTS OF THE SNOW-PIT DATA}

The quality control of the analytical data was performed by means of the crosscomparison of the ion balance and the conductivity balance. This method was used by Miles and Yost (1982) in order to control the quality of the precipitation data of the United States Geological Survey (USGS) network. The method needs specific conductivity measurements and depends upon the following assumptions:

- The analysis is deemed to be complete, i.e., it is supposed that all ions contributing to the ion balance are analyzed. 


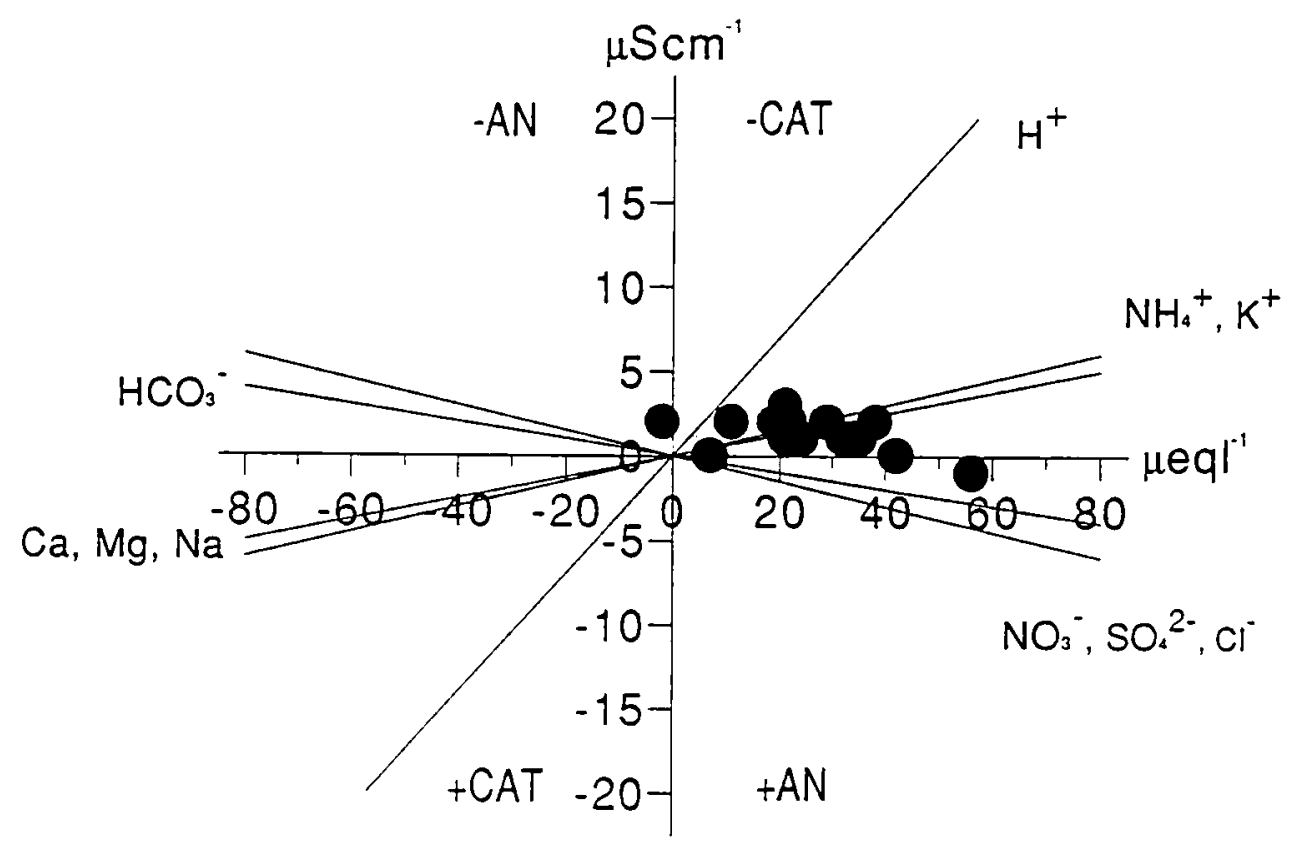

Fig. 4a.

Figs. 4(a)-(d). The difference "measured conductivity minus calculated conductivity" $\left(\mu \mathrm{S} \mathrm{cm}^{-1}\right)$ plotted versus the ion balance " $\Sigma$ anions minus $\Sigma$ cations" ( $\mu$ eq $\mathrm{L}^{-1}$ ) for the snow-pit data sets of groups 1 to 4 of the Weissfluhjoch intercomparison. Lines corresponding to ions ranked together, i.e., the angular coefficients of their limiting equivalent conductivities, are plotted to facilitate the reading of the graphs. The type of error (excess or defect of anions: +AN or-AN, excess or defect of cations: + CAT or - CAT) is indicated on the four quadrants.

- If an error occurs, it is caused by a few ions only and for the best result of the test by one ion only.

- Errors are more likely to occur during the chemical analysis than during the conductivity measurement.

A complete data set, allowing the execution of quality control (including conductivity measurements) is only available for the groups 1 to 4 . For the samples analyzed by these groups, the difference " $\Sigma$ anions $-\Sigma$ cations" is plotted against the difference "measured conductivity - calculated conductivity" (Figure 4a-d). The sum of anions and cations include $\mathrm{HCO}_{3}^{-}$and $\mathrm{H}^{+}$, measured or calculated from $\mathrm{pH} . \mathrm{H}^{+}$calculated from $\mathrm{pH}$ was corrected for the activity coefficient. since $\mathrm{pH}$ gives an activity and not a concentration while the calculated conductivity took into account the ionic strength by means of the Onsager equation. This correction is very small for low ionic strength, as is typical for snow samples. From the position of the points in relation to the axes, the type of analytical error can be deduced. In the best case, the points should be concentrated in the origin of the axes. The ratio $\triangle \mathrm{COND} / \triangle \mathrm{ION}$ is the limiting equivalent ionic conductance of the ion in 


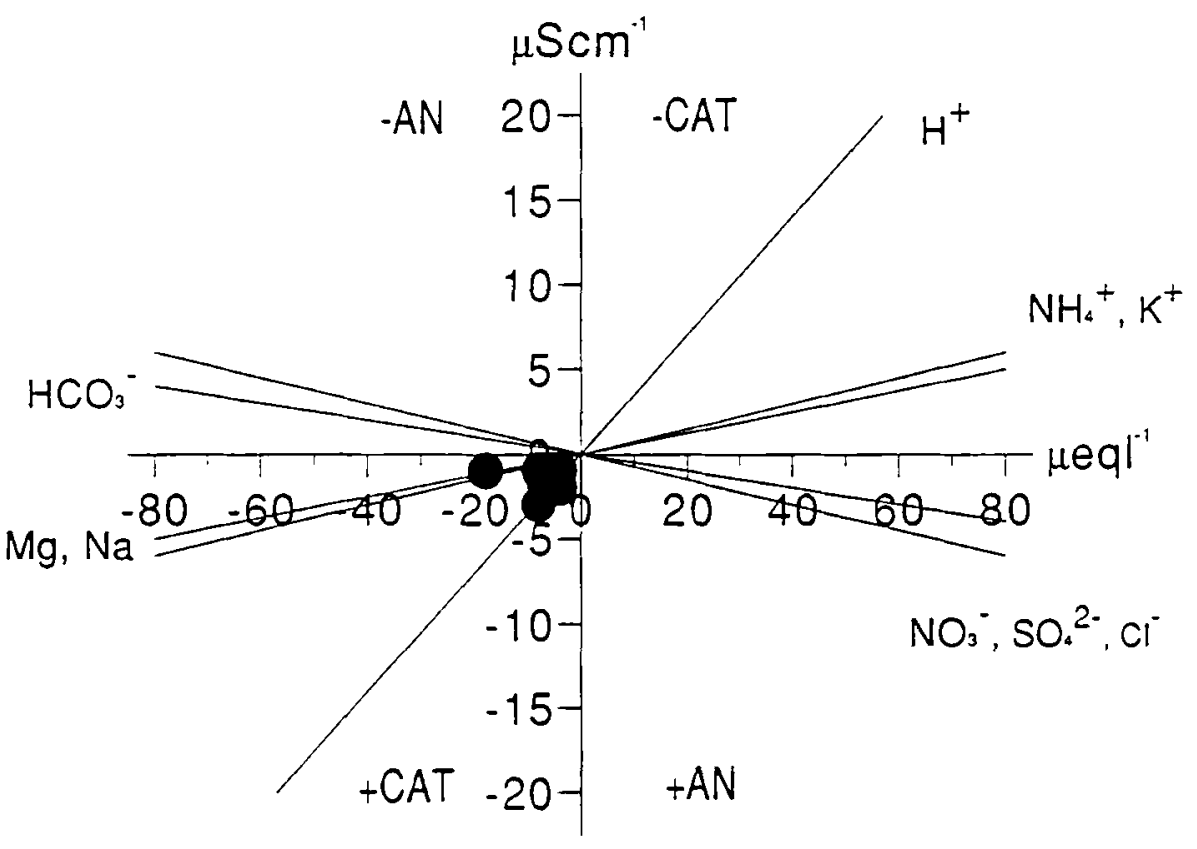

Fig. 4b.

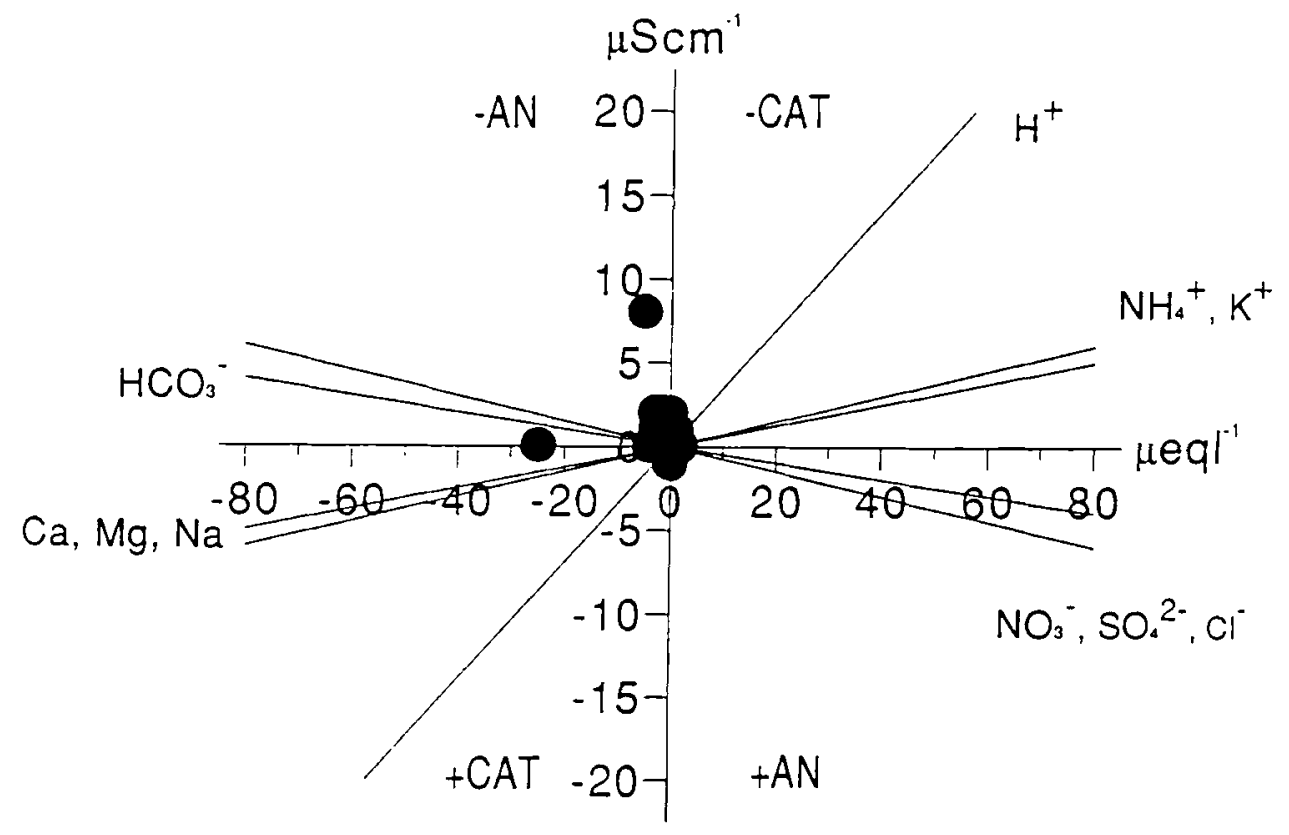

Fig. $4 c$ 


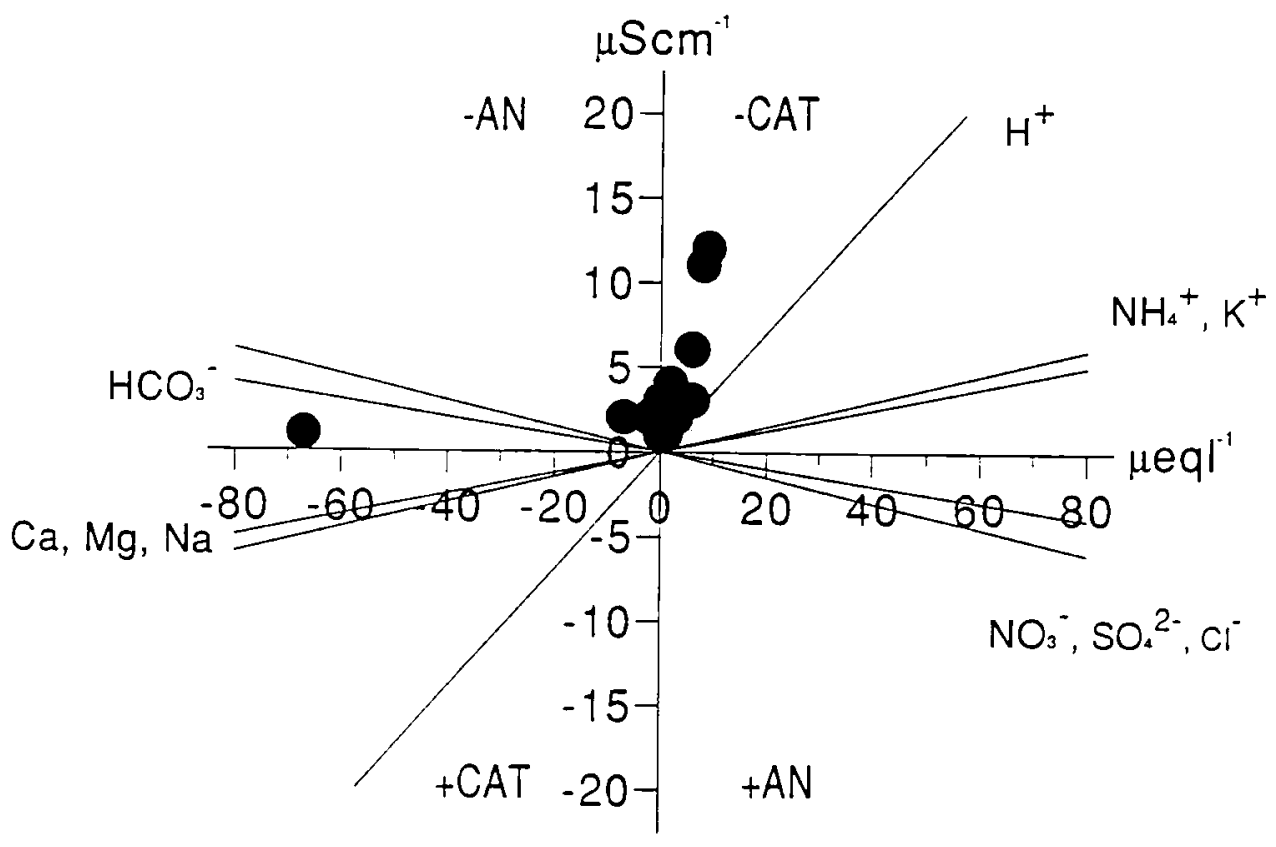

Fig. 4d.

error. From the values of the limiting equivalent ionic conductance of the ions involved, however, some ions are ranked together. This is the case for the groups $\left(\mathrm{Ca}^{2+}, \mathrm{Mg}^{2+}, \mathrm{Na}^{+}\right),\left(\mathrm{K}^{+}, \mathrm{NH}_{4}^{+}\right)$, and $\left(\mathrm{Cl}^{-}, \mathrm{NO}_{3}^{-}, \mathrm{SO}_{4}^{2-}\right)$. Both ion balance and conductivity balance are needed to attribute errors to an excess or defect of anions or cations. From Figures 4a-d it is obvious that each laboratory leaves a kind of "fingerprint" on its analyses:

- Values from group 1 lay nearly on a straight line with the same angular coefficient as $\mathrm{HCO}_{3}^{-}$, but with a positive intercept as if there is also a positive error in the conductivity measurement.

- Group 2 produced only two problematic values, and the barycentre of the points is not in the origin of the axes.

- Group 3 has problems similar to that of group 2 and, moreover, the cloud of points is slightly elongated in a nearly vertical direction.

- Group 4 produced one point showing a large anion deficit and the cloud of points is spread and elongated between the conductivity axis and the $\mathrm{H}^{+}$ deficit line.

Since $\mathrm{H}^{+}$may represent a consistent fraction of the ionic balance, additional information about the quality of the $\mathrm{pH}$ and alkalinity measurement can be obtained by comparing the acidity values calculated from the ion balance ( $\Sigma$ anions minus $\Sigma$ cations excluding $\mathrm{H}^{+}$) with those calculated from $\mathrm{pH}$ and a $\mathrm{CO}_{2}$ partial pressure of $350 \mathrm{ppm}_{v}$. For this comparison, the results of group 5 could also be included (Figures $5 \mathrm{a}-\mathrm{e}$ ). For group 1 a good agreement between the two calculated acidities 


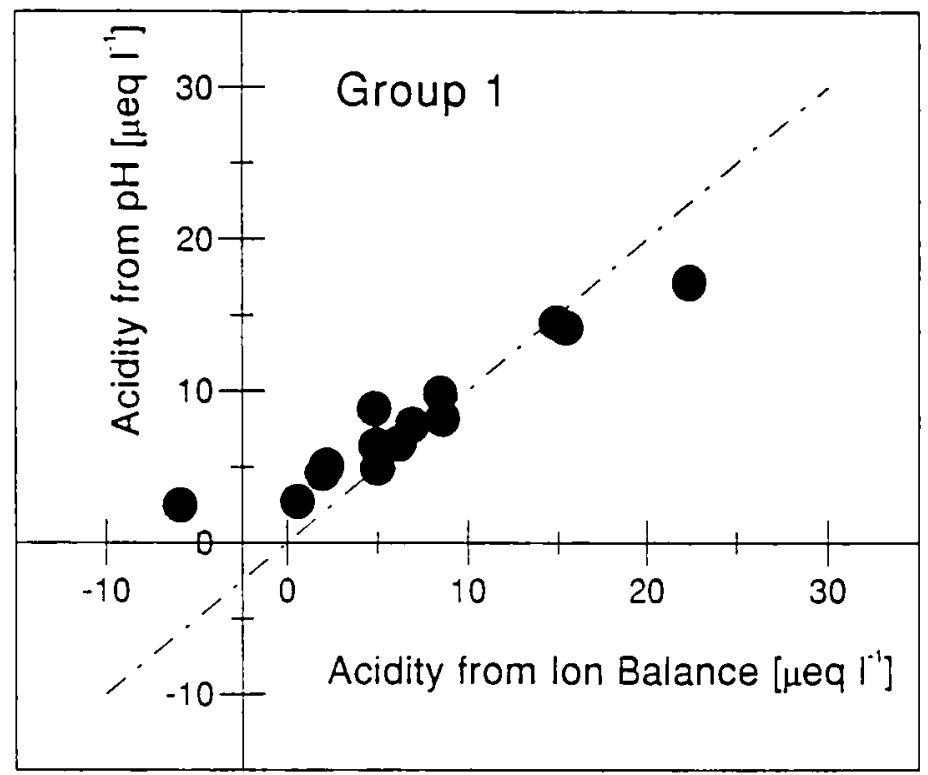

Fig. 5a.

Figs. $5(\mathrm{a})-(\mathrm{e})$. Acidity calculated from the measured $\mathrm{pH}\left(\mu \mathrm{eq} \mathrm{L}^{-1}\right)$ plotted versus acidity calculated from the ion balance " $\Sigma$ anions minus $\Sigma$ cations" ( $\mu$ eq $\mathrm{L}^{-1}$ ) for the snow-pit data sets of groups $1-5$ of the Weissfluhjoch intercomparison.

was found, except for two samples. This confirms the previous result, i.e., the measured alkalinity is overestimated. Acidity values calculated from $\mathrm{pH}$ of group 2 were always higher than those calculated from ion balance. This is in agreement with Figure 4b, showing a slight excess of cations, probably $\mathrm{H}^{+}$. For group 3 a good agreement was found between the two acidities. Acidity values calculated from $\mathrm{pH}$ of group 4 were always lower than those calculated from ion balance. Acidity values of group 5 agreed well apart from some slight differences for the extreme points.

From these two quality tests it was possible to suggest the kind of error in the analyses of the four groups with a complete data set. For group 1, data grouped themselves near the origin of the axes in Figure 4a when zeroing all the alkalinity values. However, a bias of $3 \mu \mathrm{S} \mathrm{cm}^{-1}$ remained that is difficult to explain. Data of group 2 were substantially right, with the exception of two points - one with a concentration of $\mathrm{Ca}^{2+}$ overestimated by a factor of 1.3 (see Figure $4 \mathrm{~b}$ ) and one with a pH value of 4.69 instead of about 4.8 (see Figure $5 \mathrm{~b}$ ). Data of group 3 were also substantially right, although this group did not determine the alkalinity. This indicates that alkalinity was important for only one sample (the Saharan dust

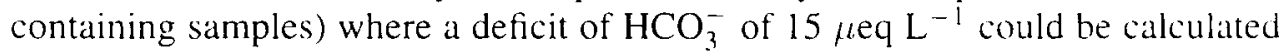




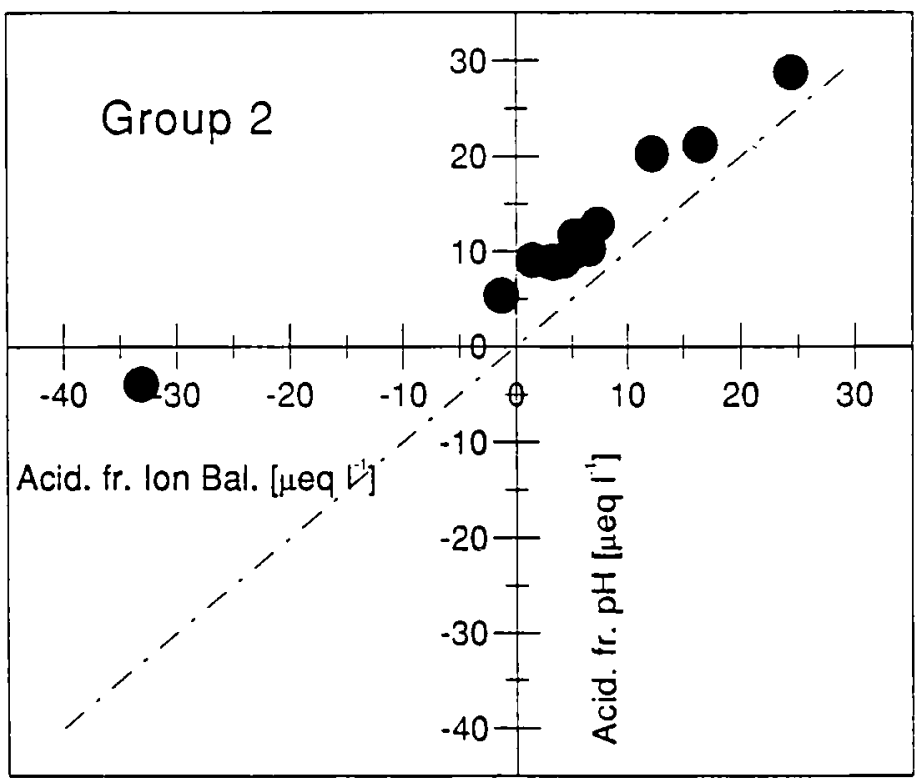

Fig. 5b.

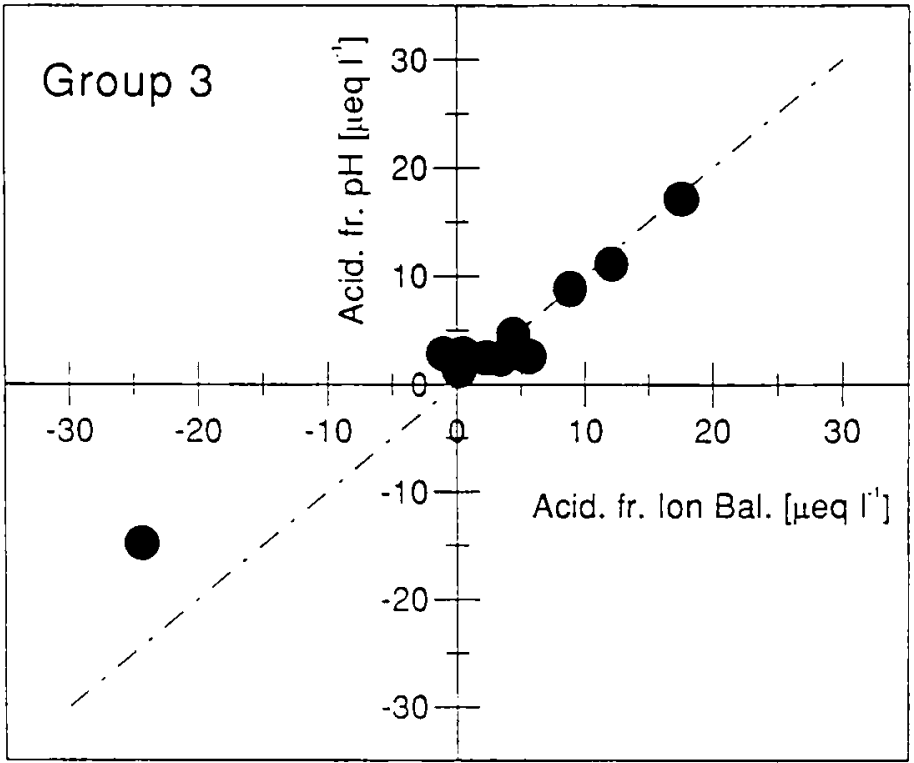

Fig. 5c. 


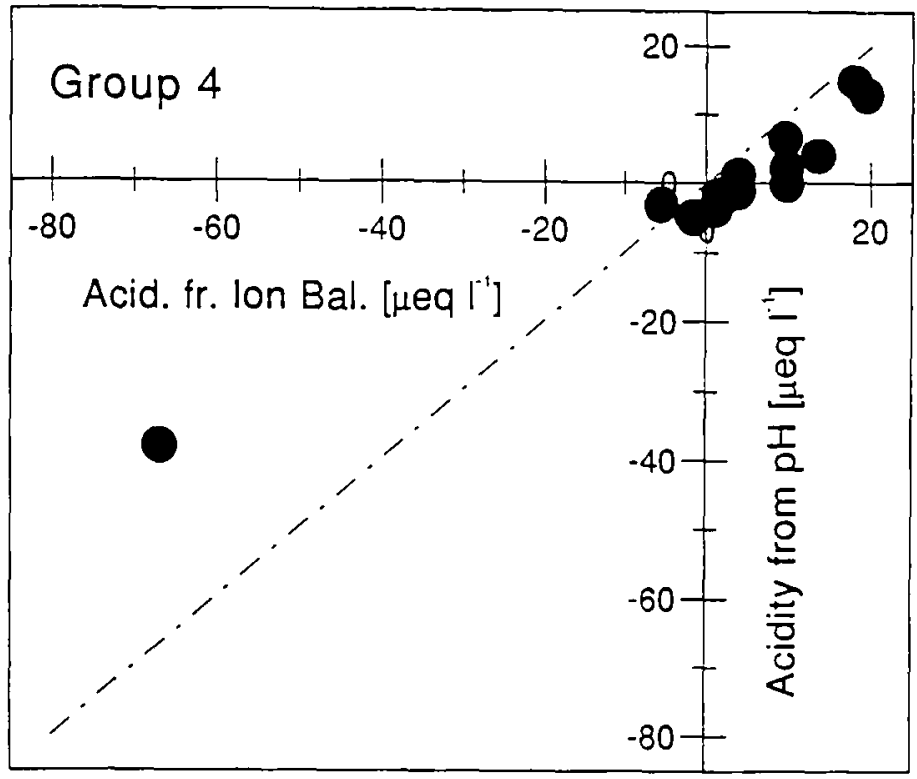

Fig. 5d.

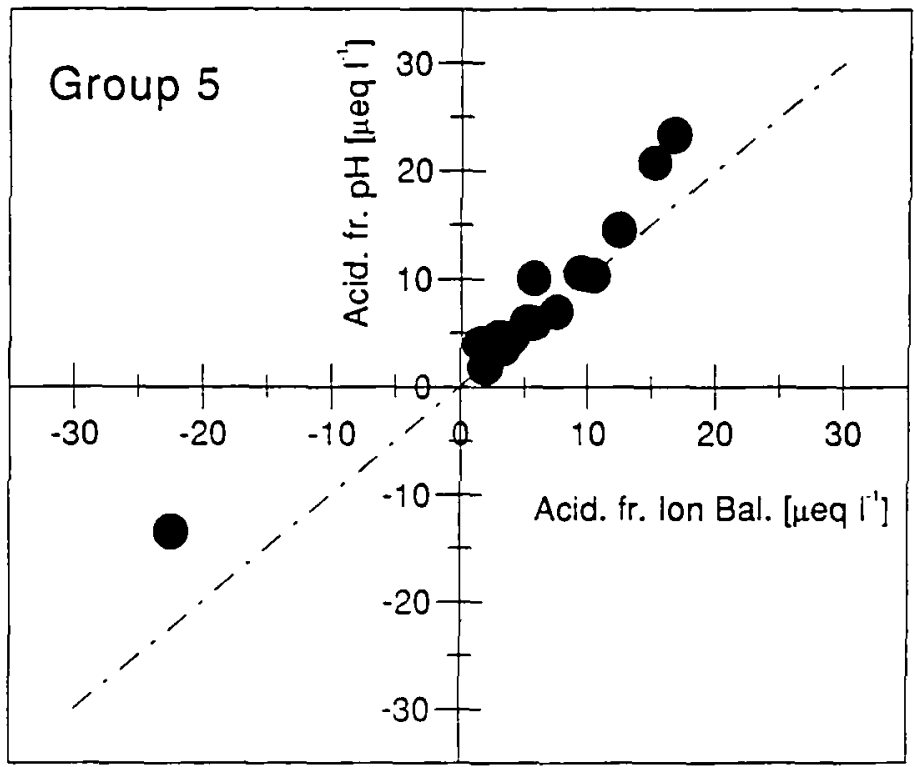

Fig. 5e. 
from $\mathrm{pH}$ (Figure 4c, outlier on the $\mathrm{y}$-axes). The reason for the other outlier far from the origin of the axes is not clear. Group 4 also did not perform the alkalinity analysis and again the Saharan dust containing sample showed a deficit in $\mathrm{HCO}_{3}^{-}$ of about $50 \mu \mathrm{eq} \mathrm{L}^{-1}$. Two other points showed a large $\mathrm{H}^{+}$deficit of nearly $10 \mu \mathrm{eq}$ $\mathrm{L}^{-1}$.

Generally, the quality test revealed that although every group left a kind of "fingerprint" on its analyses, no major systematic errors occurred in the determination of the individual ionic species (except $\mathrm{HCO}_{3}^{-}$measurements from group 1). This closer look at the analytical results confirmed the findings that $\mathrm{pH}$ measurements were less precise than analyses of most other constituents. Furthermore, it underlined the problems of alkalinity (probably associated with $\mathrm{Ca}^{2+}$ ) measurements in samples containing high amounts of Saharan dust (samples with negative acidities in Figure 5).

\section{Conclusions and Recommendations}

The two laboratory and the two snow-pit sampling intercomparisons performed among the SNOSP groups revealed a reasonable agreement between determinations of the important trace species $\mathrm{Cl}^{-}, \mathrm{NO}_{3}^{-}, \mathrm{SO}_{4}^{2-}, \mathrm{Na}^{+}$, and $\mathrm{NH}_{4}^{+}$in snow. This statement is not only valid for the chemical analysis but also for the sampling and sample handling procedures. This agreement is an important basis for the interpretation of chemical inventory data sets like the SNOSP data set with respect to, for instance, geographical deposition patterns. By considering the recommendations given below, ionic loads and volume weighted means of these species from different sites are comparable within the analytical error (relative standard deviations $\leq 17 \%$ ) and differences in ionic loads anıng the sites $\geq 34 \%(2 \sigma)$ would be significant. In the case of $\mathrm{Ca}^{2+}$ a similar result can be obtained by removing Saharan dust layers from the data set and regarding them separately. This is particularly meaningful if one considers the episodic and inhomogeneous character of Saharan dust events. The determinations of ionic species $\mathrm{K}^{+}$and $\mathrm{Mg}^{2+}$ were less satisfying, mainly because of the very low concentrations in the snow samples, which were mostly in the range of the detection limits. The differences in ionic loads obtained by individual groups for these two ions can be explained by less precise chemical analyses and were not caused by the sampling procedures. This was also the case for the $\mathrm{pH}$ and/or acidity measurements. The discrepancies in $\mathrm{H}^{+}$loads seemed to be caused by analytical problems in determining $\mathrm{pH}$ in snow samples with low ionic strength and low $\mathrm{H}^{+}$concentrations. However, the quality test showed that particularly the $\mathrm{pH}$ determination in samples containing Saharan dust, i.e., alkaline samples, was problematic. Applied to a chemical inventory data set, ionic loads and volume weighted means of $\mathrm{K}^{+}, \mathrm{Mg}^{2+}$, and $\mathrm{H}^{+}$would be statistically different if they differ by a factor of two. Thus, an improvement of the techniques used by 
the participating laboratories to determine $\mathrm{K}^{+}, \mathrm{Mg}^{2+}$, and $\mathrm{H}^{+}$seems necessary in order to quantify spatial variations among the SNOSP sampling sites.

As an outcome of the performed intercomparisons the following recommendations can be made in order to obtain reliable chemical inventories of the corresponding species from different snow pack sites.

Snow-pit samples should be collected in continuous increments of about $10 \mathrm{~cm}$, in order to obtain a good depth resolution, from the vertical pit wall. Precautions to be taken to avoid contamination are the cleaning of materials assumed to come in contact with the collected snow and the wearing of clean plastic gloves and clean clothes during sampling. Samples should be kept frozen until they are analyzed in the laboratory. Density measurements are required for each sampling increment in order to calculate deposition fluxes. The quality of the chemical analyses should be tested routinely by a cross-comparison of the ion balance and the conductivity balance. For a $\mathrm{Ca}$ inventory, episodic events like Saharan dust events should be considered separately.

\section{Abbreviations of Institutions}

BLB Biologisches Landeslabor der Provinz Bozen, Leifers, Italy

ENEL Ente Nazionale per l'Energia Elettrica, Italy

GSF Gesellschaft für Strahlen- und Umweltforschung, Germany

IAC-TUW Institut für Analytische Chemie, Technische Universität Wien, Austria

IMGI Institut für Meteorologie und Geophysik, Universität Innsbruck, Austria

IMGW Institut für Meteorologie und Geophysik, Universität Wien, Austria

IUP Institut für Umweltphysik, Universität Heidelberg, Germany

LGGE Laboratoire de Glaciologie et Geophysique de l'Environnement, CNRS, France

ÖFZS Österreichisches Forschungszentrum Seibersdorf, Austria

PSI Paul Scherrer Institut, Switzerland

\section{Acknowledgements}

We thank the Swiss Institute for Snow and Avalanche Research (E. Beck, Dr. W. Ammann) for the opportunity to collect our snow samples from their snow investigation field and for the information about the snow stratigraphy. Furthermore, we want to thank Dr. Terry Dana who organized the first laboratory intercomparison 
during his stay at the Institute of Analytical Chemistry, Vienna University of Technology, as a visiting professor. This work was part of the program ALPTRAC, which itself is a subproject of EUROTRAC. Financial support by the German Ministry for Science and Technology (BMFT), by the Swiss National Science Foundation, by the Swiss Bundesamt für Bildung und Wissenschaften and by the Austrian Fonds zur Förderung der wissenschaftlichen Forschung is acknowledged.

\section{References}

Baltensperger, U., Schwikowski, M., Gäggeler, H. W., Jost, D. T., Beer, J., Siegenthaler, U., Wagenbach, D., Hofmann, H. J. and Synal, H. A.: 1993, Atmospheric Environment 27A, 1881.

Batifol, F. M. and Boutron, C. F.: 1984, Atmospheric Environment 18, 2507.

Camuffo, D., Bernardi, A. and Bacci, P.: 1991, Atmospheric Environment 25A, 2863.

Colbeck, S. Akitaya, E., Armstrong, R., Gubler, H., Lafeuille, J.. Lied, K.. McClung. D. and Morris, E.: 1985, Report of the Working Group on Snow Classification, issued by The International Commission on Snow and Ice of the International Association of Scientific Hydrology.

De Angelis, M. and Gaudichet, A.: 1991, Tellus 43B, 61.

Delmas, R. and Aristarain, A.: 1978, in Benarie, M. M. (ed.), Atmospheric Pollution 1978, Studies in Environmental Sciences, Elsevier, Amsterdam, p. 233.

Delmas, V. M., Ronseaux, F. and Delmas, R. J.: 1988, in Unsworth, M. H. and Fowler, D. (eds.), Acid Deposition at High Elevation Sites, Kluwer Academic Publishers, Dordrecht, p. 511.

Döscher, A., Schwikowski, M. and Gäggeler, H. W.: 1995, J. Chromatogr. 706, 249.

Funk, M.: 1994, in: Haeberli, W. and Stauffer, B. (eds.), Greenhouse Gases, Isotopes and Trace Elements in Glaciers as Climatic Evidence of the Holocene, Report of the ESF/EPC Workshop, Zürich, 27-28 October 1992, p. 40.

Haeberli, W., Schotterer, U., Wagenbach, D., Haeberli-Schwitter, H. and Bortenschlager S.: 1983, Joumal of Glaciology 29, 260.

Laird, L. B., Taylor, H. E. and Kennedy, V. C.: 1986, Environ. Sci. Technol. $20,275$.

Maupetit, F., Delmas, R. J., Wagenbach, D., Geis, K., Schwikowski, M., Baltensperger, U., Gäggeler, H. W., Novo, A., Rossi, G. C., Bendetta, G., Trockner, V., Nickus, U., Kuhn, M., Winiwarter, W. and Puxbaum, H.: 1993, in: Borrell, P. M., Borrell, P., Cvitas, T. and Seiler, W. (eds.), Proc. EUROTRAC Symposium 1992, Garmisch-Partenkirchen, 23-27 March, 1992, SPB Academic Publishing bv, The Hague, p. 757.

Maupetit, F. and Delmas, R. J.: 1994a, J. Geophys. Res. 99, 16491.

Maupetit, F. and Delmas, R. J.: 1994b, Tellus 46B, 304.

Maupetit, F., Wagenbach, D., Weddeling, P. and Delmas, R. J: 1995, Atmospheric Emiromment 29, 1.

Miles, L. J. and Yost, K. J.: 1982, Atmospheric Environment 16, 2889.

Nickus, U., Kuhn, M., Pichlmayer, F.. Baltensperger, U., Delmas, R., Gäggeler, H. W., Kasper, A., Kromp-Kolb, H., Maupetit, F., Novo, A., Preunkert, S., Puxbaum, H., Rossi, G., Schöner, W., Schwikowski, M., Seibert, P., Staudinger, M., Trockner, V. and Wagenbach, D.: 1996, Tellus (submitted).

Oeschger, H., Schotterer, U., Stauffer, B.. Haeberli, W. and Röthlisberger, H.: 1977, Zeitschrift fïr Gletscherkunde und Glazialgeologie 13, 193.

Puxbaum, H.: 1991, in Borrell, P. M., Borrell, P. and Seiler, W. (eds.), Proc. EUROTRAC Symposium 1990, Garmisch-Partenkirchen, 2-5 April, 1990, SPB Academic Publishing bv, The Hague, p. 53.

Puxbaum, H., Kovar, A. and Kalina, M.: 1991, in: Davies, T. D., Tranter, M. and Jones H. G. (eds.) Seasonal Snowṕacks, NATO ASI Series, Vol. G28, Verlag Springer Berlin, p.273.

Puxbaum, H. and Wagenbach, D.: 1994, in: Borrell, P. M., Borrell, P. Cvitas T. and Seiler, W. (eds.) Proc. EUROTRAC Symposium 1994, Garmisch-Partenkirchen, 11-15 April, 1994, SPB Academic Publishing bv, The Hague, p. 597.

Ronseaux, F. and Delmas, R. J.: 1988, in Unsworth, M. H. and Fowler, D. (eds.), Acid Deposition at High Elevation Sites, Kluwer Academic Publishers, Dordrecht, p. 491. 
Schotterer, U., Oeschger, H., Wagenbach, D. and Münnich, K. O.: 1985, Zeitschrift fïr Gletscherkunde und Glazialgeologie 21, 379.

Wagenbach, D., Münnich, K. O., Schotterer, U. and Oeschger, H.: 1988, Ann. Glaciol. 10, 183.

Wagenbach, D. and Geis, K.: 1989, in Leinen, M. and Sarnthein, M. (eds.), Paleoclimatology and Paleometeorology: Modern and Past Patterns of Global Atmospheric Transpont, Kluwer Academic Publishers, Dordrecht, p. 543. 